\title{
HVMANITAS
}

\section{A sabedoria dos antigos e arte de fortificar: modelos culturais e fontes para os textos portugueses modernos sobre edificação}

Autor(es): $\quad$ Patrocínio, Manuel F. S.

Publicado por: Imprensa da Universidade de Coimbra

URL

persistente:

URI:http://hdl.handle.net/10316.2/27403

DOI:

DOI:http://dx.doi.org/10.14195/2183-1718_64_10

Accessed : $\quad$ 26-Apr-2023 00:24:43

A navegação consulta e descarregamento dos títulos inseridos nas Bibliotecas Digitais UC Digitalis, UC Pombalina e UC Impactum, pressupõem a aceitação plena e sem reservas dos Termos e Condições de Uso destas Bibliotecas Digitais, disponíveis em https://digitalis.uc.pt/pt-pt/termos.

Conforme exposto nos referidos Termos e Condições de Uso, o descarregamento de títulos de acesso restrito requer uma licença válida de autorização devendo o utilizador aceder ao(s) documento(s) a partir de um endereço de IP da instituição detentora da supramencionada licença.

Ao utilizador é apenas permitido o descarregamento para uso pessoal, pelo que o emprego do(s) título(s) descarregado(s) para outro fim, designadamente comercial, carece de autorização do respetivo autor ou editor da obra.

Na medida em que todas as obras da UC Digitalis se encontram protegidas pelo Código do Direito de Autor e Direitos Conexos e demais legislação aplicável, toda a cópia, parcial ou total, deste documento, nos casos em que é legalmente admitida, deverá conter ou fazer-se acompanhar por este aviso.

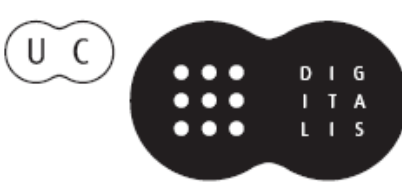


humanitas

\section{Vol. LXIV \\ 2012}

IMPRENSA DA UNIVERSIDADE DE COIMBRA

COIMBRA UNIVERSITY PRESS 


\title{
A SABEDORIA DOS ANTIGOS E A ARTE DE FORTIFICAR.
}

\author{
Modelos culturais e fontes para os textos \\ portugueses modernos sobre edificação.
}

\author{
Manuel F. S. Patrocínio \\ (Universidade de Évora, Escola de Ciências Sociais, \\ Departamento de História)
}

\section{Resumo}

O tema da edificação, abrangendo tanto a actividade construtiva como o propósito da fundação e remodelação urbana, distinguiu géneros literários específicos que, conforme o exemplo de textos referenciais, tornavam o universo arquitectónico em objecto de reflexões, comentários e métodos de intervenção. Considerar-se-ão, assim, os documentos correlativos para o período moderno, de entre o conjunto de fontes que subsistiram quanto ao contexto formativo dos edificadores portugueses de sécs. XVI-XVII, convergindo necessariamente nas elaborações textuais em que estavam subjacentes anotações correlativas ao passado antigo. Abordar-se-ão aqui alguns desses textos, datados depois de 1640, considerando o seu papel para a necessidade de fortificar o Reino, e o seu enquadramento de temáticas definidas, de valorização do construído como conducente à formação dos construtores, bem como o recurso aos Autores da Antiguidade, tal como eram citados em torno a 1650.

Palavras-chave: Herança Clássica, Cultura Arquitectónica, Ideias e Formas Monumentais, Restauração

\footnotetext{
Abstract

The edified legacy, comprehending constructive activity as well as urban creation and transformation, has given origin to specialized literary genres, among which some referential texts were distinguished by their observations and reflections
} 
on monumental heritage, besides proposing intervening methods concerning architectural practice. Such documents, mostly corresponding to modern texts, will be taken into account as sources to the knowledge of the education of Modern Portuguese builders in 16-1 $17^{\text {th }}$ Centuries, considering annotations that were referent to the Ancient past, especially in texts produced after Portuguese Restoration of 1640 , when new strategies were enrolled to the need to fortify the country and to promote military constructive programmes. Such texts show how the scientific and cultural basis deeply rooted in classical models and ancient Authors through erudition and science was still engraved as an attitude that distinguished the generation of practical constructors and commentators around 1650.

Key-words: Classical Legacy, Architectural Culture, Monumental Ideas and Forms, Portuguese Restoration

A exaltação da ciuitas como res publica, a que a materialização dos modos de edificar deveria necessariamente corresponder, origina-se nos discursos culturais da Antiguidade e regressa nos discursos da Europa moderna, percorrendo, como tema e objectivo, alguns dos principais textos que vieram a ser elaborados dirigindo-se ao edificado, à monumentalidade e à formação dos construtores. Exprimindo noções e pressupostos dirigidos ao que se deveria concretizar com a competência construtiva, tais textos correlacionam-se particularmente com o confronto entre a "cidade real" e a "cidade ideal", conforme a definição de Giulio Carlo Argan. Sobre a "cidade real", percepcionava-se por esta via uma "cidade ideal", a qual "sempre existe (...), dentro ou sob uma cidade real, distinta desta como o mundo do pensamento o é do mundo os factos", sendo a cidade também um "produto artístico ela mesma"1.

Nesta definição, a cidade tornar-se-ia ela própria em obra de arte, no pressuposto de que a intervenção arquitectónica seria uma intervenção criadora oferecida ao colectivo, contribuindo, quando se torna programa, para a definição de formas e composição que tencionam moldar o espaço envolvente de acordo com significados concebidos como ideais. $\mathrm{O}$ acto de construir para a cidade, deste modo construindo-se a cidade, era o que já os Romanos designavam de opportunitas, e em que a edificação deveria

1 Argan 1998 (1984): 73. O conceito de cidade como criação, de acordo com Argan resultava do entendimento de que "a obra de arte" era "soma de componentes, não necessariamente concentradas numa pessoa ou época"; logo sendo uma construção progressiva (cf. id., ibid.). 
exprimir os valores sublimes a que se referiam ideais sobre o próprio colectivo social, projectando-se, em toda a realização, o sentido de ordem decorrente dos próprios valores conotados com a Alma, sendo, de resto, a apologia da Alma um conceito de formulação platónica, sempre retomado como atitude fundamentadora ${ }^{2}$.

Tendo considerado a arte de edificar no Preâmbulo do seu tratado De Architectura, Vitrúvio exaltou, no séc. I, o empenho de Augusto no fomento de obras públicas, com as quais se edificou a cidade, em atitude significante que se referia à própria transcendência quanto à materialidade. Com efeito, porque, aqui, as conotações para o sentido de cidade eram tão relativas aos modos de concretização técnica, como igualmente uma concretização espiritual, poder-se-ia afirmar que "a Cidade não foi apenas engrandecida" (e tendo-o sido "através de ti", assim se dirigindo Vitrúvio ao Imperador), como "também a dignidade do Império foi sublinhada pela egrégia autoridade dos edifícios" (Vitr., I. Preâmbulo. 2)3. Mais adiante, há-de definir o conceito de ciuitas como sinónimo de território ou país, quando tratou de exaltar a boa geografia que teria favorecido a nação romana para o serviço de governar o mundo, aqui conotando-se com o sentido de espaço (Vitr., 6.1.11)4.

Desde logo, Vitrúvio apresentava a architectura como resultante de um processo histórico, e falava-se, no Tratado, da emergência das práticas construtivas desde tempos primitivos, e da cidade como ponto de chegada da memória e do progresso técnico (Vitr., 2.1.1-3) ${ }^{5}$. Deixava estabelecido que a actividade do arquitecto se deveria repartir em três domínios: aedificatio, gnomonice e machinatio, sendo aedificatio a acção de "levantar os recintos fortificados", subdividindo-se entre defensio, religio e opportunitas (Vitr.,

2 Essencial ao ideal moderno de Cidade, está a atitude de exortação ao amor pela cidade, que Platão defendeu no Banquete, sendo que, no séc. XVI, tratando da proposta de "engrandecimento" da capital do Reino, traçou Francisco de Holanda um capítulo inteiramente dedicado à "Cidade da Alma", incluído no manuscrito Da Fábrica que falece à Cidade de Lisboa (1571); cf. Patrocínio 2010: 324-325 e 332.

3 Maciel 2006: 29 (“[...] ut civitas per te non solum provinciis esset aucta, verum etiam ut maiestas imperii publicorum aedificiorum egregia haberet auctoritates [...]"; Granger 1995 [1931]: 2).

4 Granger 1996 (1934): 18 ("ita divina mens ciuitatem populi Romani egregiam temperatamque regionem conlocauit, uti orbis terrarum imperii potiretur"; em tradução portuguesa: "a divina mente dispôs a nação do povo romano numa região escolhida e temperada, a fim de que se apoderasse do império do mundo", in Maciel 2006: 225).

5 Maciel 2006: 71-72. 
1.3.1 $)^{6}$. Não menos se assinala o sentido ambíguo de tratar-se da guerra para manter a paz, segundo o que se resguarda no ideal de defensio. Certo é que, a par da edificação de templos para o dever de religio, se edificava o aparato de torres, muralhas ou portas (moemia) para se responder ao dever de defensio, ou seja, segundo o texto, "tendo em vista a rejeição contínua do ataque dos inimigos" (Vitr., 1.3.1)

$\mathrm{O}$ referente vitruviano, muito subjacente à cultura moderna, e tendo instituído o género tratadístico como categoria literária enquanto referente clássico para a cultura arquitectónica, estará sobretudo presente nas formulações que retomam o primado das ordens, bem como os princípios técnicos, fixando especial atenção na componente de aedificatio que, para a proposta de Vitrúvio, era porém somente parte de uma actividade mais abrangente. De facto, governar a cidade, era, decorrentemente, construí-la e defendê-la; e a arte de edificar era também arte de fortificar, estruturando-se uma prática (ou ars) e um conhecimento (scientia) que se revestia de diversas partes, ainda que interligadas entre si. O tratado vitruviano é o precedente da exigência fundamental da necessidade prévia do texto quanto à actividade edificatória.

Em momentos modernos, os textos sobre edificação proliferariam fundamentalmente depois do séc. XV e a seguir a outro legado instaurador, de Leon Battista Alberti (1404-1472), integrando-se na afirmação cultural da Europa Moderna e acompanhando o fomento de programas e incremento de debates filosóficos sobre o valor da beleza e da exigência do sentido de aplicação da medida. As obras de Alberti, nomeadamente Descriptio urbis Romanae (1443) e De re aedificatoria (1452), concretizariam a emergência da nova tratadística arquitectónica e do novo pensamento quanto ao arranjo urbano, ainda que a literatura dirigida ao construído viesse repartir-se por mais géneros subsidiários, convergindo, nomeadamente, na progressiva autonomização dos tratados de arquitectura militar ${ }^{8}$. Ou originando textos de descrição dos vestígios monumentais da Antiguidade que, no caso da própria Roma constituíam uma verdadeira "outra" cidade debaixo da urbe moderna. E em breve, como, de resto, Francisco de Holanda é bem exemplo com as suas notícias sobre os vestígios romanos olisiponenses,

6 Maciel 2006: 40.

7 Maciel 2006: 40.

8 "Fortification was largely an independent genre of architectural writing in the sixteenth century" (Wilkinson 1988: 467). 
também noutras urbes se assinalou a procura do construído como modo de evocação da dignidade dos lugares ${ }^{9}$.

Considerou Françoise Choay uma divisão de tais escritos, que, tratando "o espaço construído e a cidade", comportaria assim duas categorias essenciais, seja enquanto textos realizadores, seja como textos comentadores, onde o tom especulativo adquire alguma preponderância: caso da Utopia, de Thomas More, enquanto expoente imaginativo tendente a um teor de recriação fantasiosa. O objectivo dos textos referir-se-ia ao desígnio desse plano ideal em que se colocava a necessidade de construção da cidade. Definindo esta distinção, explica-se, quanto às categorias de textos, que "os primeiros contribuem para a produção do mundo construído, para a edificação de espaços novos", e os segundos "privilegiam ou não a imaginação, a paixão ou a reflexão, não pretendem sair do universo do escrito" 10 .

Afastando-se de teorizações, porque era cada vez mais uma missão prática, o serviço da aprendizagem e formação na Europa Moderna, além do recurso aos tratados, em breve traria também consigo o aparecimento dos compêndios de funcionalidade evidentemente escolar, que decorrem como recurso indispensável do saber, surgindo então como textos realizadores. Convergiam no objectivo de edificar a cidade de acordo com os cânones modernos em que decorreu a consolidação dos sistemas de formação dos agentes construtores, indistintamente congregando "engenheiros" e "arquitectos", porque se tratava de uma mesma competência técnica11.

Precisamente o que sucedia no contexto moderno português, protagonizando-se a realização monumental do Reino e territórios do Império onde foi necessário estabelecer portos e fortalezas, assiste-se ao fomento de Aulas régias ou academias ligadas à Corte onde se preparavam os construtores. Em tradição que é possível restituir, há notícia de uma primeira diligência quanto a uma "Aula da Sphera", consagrada então ao ensino matemático, que teria começado a funcionar em casas que o Infante D. Henrique comprara por volta de 1440, depois doadas para arranjo da instalação da Universidade, em Lisboa (à actual Rua das Escolas Gerais) onde ainda funcionariam em

9 Cf. Patrocínio 2006 e Patrocínio 2010.

10 Choay 2007: 25.

11 Para a temática, cf. Choay 2007, Moreira 1987, Smith 1993: 1-25; Tiago de Oliveira 1989; Wilkinson 1988. 
tempo de D. Manuel I, e que, por hipótese, convergia para o serviço dos empreendimentos marítimos ${ }^{12}$.

"Aula da Esfera" foi mais propriamente a designação do curso que veio reunir as matérias de Matemática e Astronomia, posteriormente distinguindo-se como o domínio de scientia em que, já em instâncias do séc. XVI, se consagraram personalidades como D. João de Castro (1500-1548), autor de Roteiros cartográficos e depois Vice-Rei da Índia, ou Pedro Nunes (1502-1578), nomeado Cosmógrafo-mor em 1527, enquanto eminentes figuras envolvidas no estudo, como no serviço do Reino ${ }^{13}$. Pedro Nunes, foi, mais particularmente, o autor da célebre tradução do Tratado De Sphaera (1537), do original de João de Sacrobosco, monge do séc. XIII, e igualmente do Tratado de Álgebra em Aritmética e Geometria (escrito ca. 1545, edição de 1567), cabendo-lhe o mérito da primeira tradução portuguesa, perdida, de Vitrúvio ${ }^{14}$. Medindo-se o mundo, abrindo-se o espaço físico ao alcance da razão, dirigida à utilidade do momento, é de realçar que, ainda em finais de séc. XVI, escrevia-se o Tratado de Perspectiva de António Rodrigues (1576), prosseguindo o magistério de Pedro Nunes e reunindo o resumo das lições de Euclides, Vitrúvio e, considerando a época, a aplicação do saber dos recentes tratadistas (como Sebastião Serlio) ${ }^{15}$.

Paralelamente à consagração do ensino universitário, as Aulas terão instituição própria, como no caso da Aula do Paço da Ribeira, que, depois de 1536, se estabeleceu por determinação real. A Aula do Paço precedeu, por sua vez, a criação em finais do séc. XVI, da Aula da Esfera no Colégio de Santo Antão de Lisboa, dos Jesuítas, onde esteve António Rodrigues, tendo ambas coexistido com outras aulas de Matemática, Geometria e Astronomia que decorriam nos colégios universitários de Coimbra e também de Évora; a especificidade formativa das Aula régia, referia-se, de qualquer modo, à educação dos príncipes e dos nobres. No séc. XVII, surgirá, depois de 1640, a Aula de Fortificação, também régia, por diligência e decreto de D. João $\mathrm{IV}$, em que se reatava a herança portuguesa dos momentos anteriores, sendo

12 Cf. Tiago de Oliveira 1989: 10-11.

13 Refere Luís de Albuquerque que "o nome de 'aula da esfera' teve decerto origem no facto de serem em geral designados por tratados 'da esfera' os textos medievais, que são numerosos, dedicados à exposição dos princípios da cosmografia” (Albuquerque 1974 a: 129).

14 Albuquerque 1974 a: 143, Moreira 1987: 65-67, Tiago de Oliveira 1989: 14-15, 37-39, 48-50.

15 Moreira 1999: 353-ss., Tavares 2007, Xavier 2006. 
que a Escola da Ribeira terá sido de alguma forma trasladada para Madrid, na ocasião da nova dinastia filipina, convergindo noutras propostas ${ }^{16}$.

Da documentação correlativa ao funcionamento das referidas Aulas e ao teor dos conteúdos ensinados, conhecem-se alguns textos científicos e técnicos, entre o já citado Tratado de António Rodrigues, ele mesmo arquitecto, e outros de missão evidentemente pedagógica, que se destinavam à preparação das competências edificatórias, à época incluídas entre as designadas Matemáticas. O saber evidenciado ainda assentava na base de conhecimentos que vinham da Antiguidade, combinados com o sentido de observação e experiência, porém já apanágio de Quinhentos e Seiscentos, num repertório de exposições e saber consolidado que assim se mantinha ${ }^{17}$.

Na verdade, o conhecimento do mundo, enquanto espaço de grandezas finitas, interpretava-se no enquadramento da aprendizagem dos Elementos de Euclides (séc. IV a.C.). A Geometria contida no Tratado de Perspectiva de António Rodrigues, do séc. XVI, reveste-se, evidentemente, de bases euclidianas: ponto, linha, construção figurativa, cálculos de ângulos, os quais permitem perceber e representar matematicamente a finitude do espaço e da figuração dos objectos - e, por fim, construí-los. No séc. XVII, o Padre Simão Falónio, Mestre do Colégio de Santo Antão (Lisboa) até à data da sua morte em 1642 e tendo sido ainda por dois anos Engenheiro - Mor do Reino imediatamente após a entronização de D. João IV, distinguir-se-ia, também, pelo saber euclidiano, que expôs na Lição de Matérias Matemáticas (ca. 1638) ${ }^{18}$.

Os exemplos mencionados obedecem a uma intencionalidade que tanto decorre do propósito mais abrangente de explicitações científicas como do propósito subsequente de fundamentar e preparar a actividade dos edificadores - lado a lado com os navegadores. Se outras obras correspondem, de facto, à divulgação que fazia parte da cultura internacional com origem na Europa, neste caso prefigura-se mais particularmente o âmbito do que veio a ser escrito pelos participantes das Aulas régias portuguesas.

16 "O fundador da nova dinastia não apenas restituía a velha tradição do ensino científico vinculado à Corte (...), como também criava o instrumento que, durante século e meio dominaria a teoria e prática da arquitectura em todo o espaço português" (Moreira 1986: 83; cf. também Moreira 1987).

17 Cf. Albuquerque 1974 a: 127-ss., Moreira 1987: 65-77, Moreira 1989: 492-494, Tiago de Oliveira 1989: 12-22 (cf. também Mello e Leitão 2005: 96-106).

18 Albuquerque 1974 a: 149, 183-185. Cf. também Albuquerque 1974 b e Heath e Toomer 1970: 413. 
O confronto assinala-se entre a escassez de testemunhos para os períodos de apogeu da Escola do Paço e o maior número de referências para a Escola de Santo Antão, e, já no séc. XVII, para a Aula de Fortificação, em que, de acordo com a exigência dos programas militares, na reactualização do ideal de defensio, se difundem textos portugueses claramente destinados a apresentar modelos construtivos, culminando no Tratado de Luís Serrão Pimentel, Método Lusitano de Desenhar Fortificações (1680).

Da actividade da Aula de Fortificação de D. João IV do protagonismo de Luís Serrão Pimentel (1613-1679), designado a Engenheiro - Mor do Reino em 1673, e antecedendo, como preparação, o seu Método Lusitânico (que teria somente edição póstuma), subsistiu o manuscrito de 1659, Lição de Architectura Militar ou Fortificação, correspondendo a uma cópia assinada pelo seu colaborador e presumível discípulo, D. Diogo do Pardo Osório ${ }^{19}$. De Pardo Osório há, contudo, menos informações, sabendo-se muito embora que, em anos posteriores, desenvolveria projectos correlativos com fortificações de Sesimbra, Setúbal e no Alentejo, cabendo-lhe a atribuição de alguns riscos; terá começado a sua actividade na Aula da Restauração, junto de Pimentel ${ }^{20}$.

Ao longo do texto, realça-se, antes do mais, a nota de actualidade, enumerando -se os recentes tratadistas de arquitectura militar: Adam Freitag, apresentado como "Adão Frittach", que escrevera Architectura militaris nova (Leyden, 1631). Igualmente referido é Mathias Dögen (ou "Mathias Dogeno"), autor de Architectura militaris moderna (Amsterdão, 1647), enquanto importantes notáveis que, comprovadamente, influenciaram os Engenheiros portugueses da Restauração. Ao lado da chegada de especialistas estrangeiros, sobretudo franceses (Cosmander, Langres, Lescole, e Jean Gilot, discípulo de Descartes), a influência teórica das lições de autores como Freitag e Dögen, ou também Samuel Marolois, Nicolau Goldmann e

19 Pimentel e Osório 1659, guardado na Biblioteca da Ajuda (Lisboa). Agradecimentos a Margarida Tavares da Conceição pelas indicações quanto a este manuscrito.

20 Da obra de Pimentel, "a maior parte (...), conservou-se através de cópias e apontamentos das lições tiradas por esses discípulos de que tanto se orgulhava"; precisamente, caso do manuscrito de 1659 (Moreira 1986: 84). Pardo Osório, que foi também projectista, terá "obra menos conhecida", mencionando-se um outro tratado de engenharia militar da sua autoria, que se perdeu mas conservando-se a seu respeito a referência posterior de Diogo Barbosa (apud. Serrão 2003: 139). 
o Barão de Coëhorn, sobre a qual se decidiu a concepção das fortificações seiscentistas portuguesas ${ }^{21}$.

Além da base teórica tais tratadistas militares, surge o recorrente apoio à citação dos Autores antigos, em aspectos que reconduzem textos como o presente manuscrito lavrado por Pardo Osório ao âmbito da cultura clássica, muito embora comece o texto desta Lição por exposições introdutórias que recorriam, antes do mais, a factos ainda mais anteriores da memória cultural, inevitavelmente retirados da Bíblia. Evocava-se, portanto, como primeira citação, o "fundador Caim", salientando-se que "da antiguidade" desta arte e/ciência, não havendo outra "individual/ notiçia", era "porem" certo constar ser "Cain o primeiro que edificou a Cidade Henoch, do nome de hum/ dos filhos, segundo a openião de alguns e no norte/ libano, começando logo os que lhe sucederão/ a funda-llas em lugares fortes que tivecçem todavia/ a rroda terrenos ferteis" 22 .

Prosseguindo-se o que das "excelencias e utilidades desta Arte [de edificar],// se pode dizer mui largamente", cabia a evocação seguinte a um romano, quanto a quem se deviam recuperar "humas palauras"; tratavam-se das afirmações "do famoso Vigecio, es/critas ao Emperador Valentiniano no seu livro de/ re militare, (...)", e que afirmara: "quem pode duvi/dar ser a Arte bellica que leva o principado entre as mais tendo/ por cauza final, que se adequa e se toma o motivo/ dos louvoures de cada huma, a retenção da liberdade,/ a propagação da dignidade do Reino ou Provincia,/ e a concervação do Império?"23.

Organiza-se o manuscrito entre um Prohemio e uma introdução subdividida em duas partes, a que se segue a considerável parte principal, que, a partir da folha 115, expõe amplamente as regras de se fazerem as "praças regulares". A introdução compõe-se então entre um "Compendio de Geometria pratica e especulativa" e um "Tratado compendioso de trigonometria rectilinea", ao longo da qual se concede grande atenção e desenvolvimento à enumeração das Proposições de Euclides ${ }^{24}$. A proposta

21 Em fase antecedente à influência dos modelos do Marquês Sebastien Le Preste de Vauban, "são agora as escolas holandesa e alemã de fortificar que predominam, com fortificações desenhadas para o interior do polígono, perfis escalonados e taludes naturais adaptados ao terreno (...), e abundância de obras externas" (Moreira 1986: 76).

22 Pimentel e Osório 1659: Proem., fl. 1. Cf. também Gn., 4.

23 Pimentel e Osório 1659: Proem., fl. 1vº.

24 Corresponde respectivamente esta divisão às seguintes partes: fls. 1-1vº fls. 2-54; fls. 54-115; fls. A partir da fl. 115 o "Livro de Arquitectura Militar ou Fortificação das Praças 
dirigia-se à competência de desenhar de figuras e compreender problemas, desde a explicitação do que eram pontos, linhas, superfícies, definindo-se as suas propriedades. Define-se, por exemplo, que se entendia por "superficie" o "que tem longitude, e lati/tude e que he diuizivel a ambas, e nao tem profun/didade; e portanto se deue considerar com o/ entendimemto, por nao auer superficie fora do/ corpo, a esta compara Proclo a sombra dos cor/pos (...), por que cahindo a qualquer outro,/ fica tendo latitude, e longitude, e nao tem profun/didade" 25 .

A ciência de Euclides corroborava definições operatórias fundamentais, como na passagem da "Deffenição 21 " sobre o "triangulo acutangulo", que "he o que tem todos os tres/ angolos agudos", havendo de "admitir[-se] que nenhum trian/golo pode ter mais que hum angolo recto, nem/mais que um obtuso E o que tiuer recto, não pode/ ser obtuso, nem pello contrario; e isto se colhe da/ preposição 32 do [Livro] $1^{\circ}$ de Euclides porquoanto con/forme a elle, os tres angolos de qualquer triangolo,/ sam iguais a doas rectas"26.

Contendo o manuscrito uma parte final, de Digressão, e ainda quanto a considerações sobre Geometria, refere-se Platão, e o modo como resolvera, na Academia de Atenas, uma célebre questão matemática, exposta em vários Problemas, de que era "o primeiro Problema dos sinco principais/ que ate gora serão resoluueis Geometricamente,/ como se possa desdobrar hum cubo sem variar sua/ forma. Nasceu esta preposição da resposta que/ deu o oraculo de Appolo em Dellos aos Delios/ opprimidos de huma grande peste; porque sendo consultados sobre o remedio della, respondeu que/ então cessaria, quando o Altar que ao mesmo/ Appolo [se] estaua Leuantando, sera de figura// de figura [sic.] cubica, fosse dobrado sem variar/ a forma" 27 .

A par da Geometria, estavam igualmente presentes as citações das Letras porque se referiam ao significado das acções que cabiam ao Homem,

regulares" comportará 71 capítulos, ocupando a sua última secção (de como "reduzir os pés cúbicos, ou corpóreos/ a palmos cubicos"), as fls. $776 v^{\circ}-780 v^{\circ}$.

25 Prosseguindo, e em referência à figura que se colocava em anexo a esta descrição, concluía-se que "esta superficie se deue imaginar que/ resulta do correr de huma linha atravessada, como na superficie ABCD.e daqui vem a/ ficar diuizivel segundo duas demençois, longi/tude e latitude, porque por razão da longitude/ da linha, fica diuizivel nesta parte" (op. cit., fls. $\left.2 \mathrm{v}^{\mathrm{o}}-3\right)$.

26 Azevedo e Osório 1659: fl. 7v․ O triângulo e as suas formas de composição, bem como ângulos, são evidentemente exemplo de figuras constituídas como superfícies geométricas. Agradecimentos a $\mathrm{M}^{\mathrm{a}}$ do Céu Tereno pelas suas explicitações sobre Geometria.

27 Op. cit.: fls. $32-32 v^{\circ}$. 
fosse quanto às anotações recolhidas da Eneida de Vergílio, como nos Fastos de Ovídio, na História Natural de Plínio-o-Antigo, ou na própria obra de Vegécio, surgindo regularmente as respectivas citações nas margens das folhas ${ }^{28}$. Idêntico procedimento para Políbio e Tito Lívio, quando se tratava de evocar as fundações militares cartaginesas, em confronto com romanas ${ }^{29}$. Era Tito Lívio que teria informado que "os Romanos preçediavão [sic.] os povos Con/quistados com Colónias que a elles transferi/ão, aquartelando-as em lugares Comodos que forti/ficavão"30.

Significativa é a menção a "Vigécio", ou seja Flávio Vegécio Renato, autor de Epitoma rei militaris, datável de finais do séc. IV d.C., sendo esta obra um tratado de organização e prática da vida militar, do período tardo-romano ${ }^{31}$. Igualmente significativa será a referência a Proclo, conhecido como Proclos Diadochos, e que, até à sua morte ca. 485 d.C., esteve na Academia ateniense, que dirigiu, distinguido-se como sábio neoplatónico, com extensa obra que incluía uns Comentários Teológicos e os Comentários a Euclides. Vegécio e Proclo, ao modo de figuras também inspiradoras para a Lição de 1659, emergem, assinaladamente de fases finais da cultura antiga, como um referente de tardo-classicismo. Em contraposição com Vegécio, um Romano cristianizado mas ainda escrevendo para o Império, Proclo, nas suas obras, subscrevia a devoção pagã; mas também é considerado um "moderno" quanto ao seu tempo, devido a um trabalho de reflexão enquadrado num sentido de idealismo espiritual, que caracterizou afinal os sécs. IV-V, e que está não menos patente em aspectos que se prendem com atitudes próximas da entrega piedosa na sua criação poética ${ }^{32}$.

Vegécio e Proclo terão sido sobretudo citados no Renascimento, facto que se torna mais raro no séc. XVII. De qualquer modo, é também sabida a influência que os Autores da Antiguidade Tardia mantinham na Europa moderna, incluindo-se aqui os narradores da Historia Augusta (sécs. III-IV), e o que traziam de sentidos épicos, associados à descrição dos colectivos bélicos em entrega heróica. A inspiração seria moral, os exércitos seriam como mãos que, com a sua destreza nas armas, protegiam o coração e a cabeça da sociedade. Com efeito, narrando as lutas de

28 Id., ibid.: fl. $33 \mathrm{v}^{\circ}$.

29 Id., ibid.: fls. $116 \mathrm{v}^{\circ}-117$.

30 Id., ibid.: fl. 117.

31 Cf. Monteiro e Braga 2009, para a recente tradução portuguesa e edição crítica desta obra.

32 Brasillach 1950: 475-478, Dodds 1970: 880, Rocha Pereira 1979: 137. 
Juliano na Pérsia, onde o mesmo Imperador perderia a vida, Amiano Marcelino usava descrições como "feroz luta", "embate dos escudos" e o "assobio dos punhais" para compor uma cenografia literária alusiva aos lugares de defrontamento ${ }^{33}$.

Não menos traziam os Autores tardios algo de um imaginário construtivo, que, na verdade, se correlacionava com os próprios factos dos sécs. IV-V, definidos por uma igualmente intensa actividade edificadora que, embora iniciada durante a pax constantiniana, acaba necessariamente por responder às questões das guerras contra as incursões bárbaras. É com Valentiniano I (reg. 364-375), e seus sucessores, entre os quais Teodósio I (reg. 379-395), e a quem Vegécio dedicou o seu Compêndio, até Valentiniano III (reg. 425-455), que decorre o ciclo início de tal fomento fortificador, em que se manifesta ainda a expressão da arquitectura militar, em que, sob as novas muralhas, e em antigos perímetros, desmantelaram-se e alteraram-se as estruturas de templa, theatra, balnea... ${ }^{34}$ No Panegírico de Cláudio Mamertino surgia referência a esta "renovação das muralhas das cidades", como uma "repentina juventude" das cidades ${ }^{35}$.

Possibilitar-se-á a hipótese de um confronto discursivo entre momentos culturais diferentes, porém em que se repete uma correlação entre ciclos de fomento construtivo e o aparecimento de textos significativos referente às obras de edificação e defesa do que pudesse entender-se como a cidade, onde intervém a arte das fortificações. No séc. I, Vitrúvio escreveu para o Império e Tito Lívio escrevia para a res publica. No séc. IV, Vegécio escrevia no tempo das reconstruções romanas de período de conflito com os Bárbaros. De alguma forma, a inspiração e o exemplo ressurgia no contexto moderno, em que igualmente a literatura consagrada às fortificações militares emerge numa circunstância de conflitos prolongados de guerra entre Reinos.

De interesse, ainda para o séc. XVII, outra vertente literária onde se esboçavam intenções de alguma forma historiográficas, de procura do sentido de nacionalidade pelo rumo ao passado e apontamento quanto aos

33 Amm. Marc., Hist., 25.1-4 (apud. Mellor 1998: 516).

34 Por outra parte, o Codex Theodosianus, que contém os Éditos imperiais de 391-392, ordenava o encerramento de templos, proibição de sacrifícios, e dos rituais de consagração de altares a divindades pagãs (Harl 1990: 7).

35 In Maciel 2000: 140-141. Sabe-se que coube também aos Imperadores Constâncio II (reg. 337-361) e Juliano (reg. 360-363) algumas acções de fiscalização e leis sobre espaço urbano, aumentando impostos sobre os residentes, condicionando as edificações privadas (cf. id., ibid.). 
vestígios arqueológicos e monumentais testemunhando a própria antiguidade e importância da ocupação do território, sendo esse o tema essencial de comentário e exortações que exaltavam o significado da remota fundação das cidades portuguesas. Tiveram posteridade Frei Bernardo de Brito, autor de Monarquia Lusitana (ca. 1600); Frei Nicolau de Oliveira e o seu Livro das Grandezas de Lisboa (1620); António Coelho Gasco, autor de Antiguidades da Mui Nobre Cidade de Lisboa (1623-1630), ou Luís Marinho de Azevedo e Fundação, Antiguidades e Grandezas da Insigne Cidade de Lisboa (1652). Todas estas referências aproximam-se da qualidade de textos comentadores, segundo a proposta de Françoise Choay, sendo que a sua atenção dedicava-se, descritivamente, à cidade, ao legado edificado e militar e ao sentido ideal da cidade como fortaleza espiritual, através de volumes onde abundava perícia erudita - nem sempre rigor interpretativo ${ }^{36}$.

Dividido em várias partes, e na qualidade de um texto comentador quanto aos cenários monumentais, o Tratado de Azevedo, menos conhecido, enumerava o que se poderia explicar atrás dos achados de colunas, painéis esculpidos ou inscrições olisiponenses, apresentadas como "pedras de tempo de Romanos, com que abonar suas antiguidades" ${ }^{37}$. Das origens de Lisboa, recapitulava, entre a lenda e a sua corroboração, a suposta fundação bíblica por Elysa, neto de Noé, de onde a plausível origem etimológica de Olisipo como Elysiopolis (bem como de Lusitânia como Elysitania, ou seja "território de Olisipo", alargando-se ainda ao epíteto de "verdadeiros Campos Elísios".... ${ }^{38}$. Foi só depois que o homérico Achiles viera refugiar-se no sítio que, por "corrupção", ficaria conhecido como Chelas e onde teria havido um antigo Templo da Deusa Tétis, abrigo para o herói, tendo inevitavelmente restado algumas demais "pedras" debaixo do "Mosteiro de Achelis" (Convento de S. Félix) ${ }^{39}$. Aí o encontrou Ulisses, na sua vez de chegar ao território, refundando-o simbolicamente a partir do momento em que colocou alicerces para um outro templo e uma torre; situar-se-iam

36 Cf Patrocínio 2010: 323-ss e Patrocínio 2006: 17-ss. Ver, ainda, Mello e Leitão 2005: 106-ss.

37 Azevedo 1753 (1652): Introdução, nota 2.

38 Azevedo 1753 (1652): 1.3., 11-13; as fontes citadas por este outro engenheiro são, porém, aqui, recentes, referindo André de Hoyos ou Frei António Brandão como autoridade para o assunto.

39 "Tétis escondeu Aquiles (...) em um templo de virgens vestais, junto da praia do mar"; Azevedo 1753 (1652): 2.1., 1-6. 
no alto da colina do Castelo de S. Jorge, restando a torre ${ }^{40}$. "Tudo isto", indicava-se, estava nos Autores antigos, Possidónio de Apameia, Artemidoro, Asclepíades; os mesmos, aliás, que haviam servido de fonte à Geografia de Estrabão ${ }^{41}$.

Traziam-se para cenário lusitânico os episódios da herança de memórias do próprio mundo clássico e bíblico. Acompanhando a sucessão de épocas, refere Azevedo que havia notícia do templo ulisseico ter sido visitado por Amílcar, na época cartaginesa, e, na ocasião de outro afamado périplo, também por Catão... ${ }^{42}$ Prosseguindo, refere, dos vestígios romanos a inscrição de "homenagem dos olisiponenses" a Octávio Augusto ${ }^{43}$, ainda que, dos seus sucessores mais próximos, e até Vespasiano, não se achasse mais "cousa que poder escrever" que vestígios de mármore jaspeado (da Igreja de S. Tomé) e uma estátua consagrada a Lúcio Cómodo ${ }^{44}$. Decorreria por fim um salto até ao período dos Mártires, para explicar a origem do topónimo Santos, dos olisiponenses Veríssimo, Máxima e Júlia, perseguidos e supliciados na época de Diocleciano, constando depois como, na "praia", em sua memória "a piedade cristã edificou uma igreja" 45 .

Exemplificando a atenção ao vestígio construído e indicando um modo como a dignidade conferida pelo passado antigo e clássico se pretendia em continuidade para o presente pela presença da memória, os textos comportavam, apesar da interpretação dúbia e fantasiosa, um notável exercício de erudição e confronto de fontes, que, assim, proporcionavam citações com que se fundamentava um assinalado discurso cultural. $\mathrm{O}$ recuo à Antiguidade também caracterizava a composição de outros textos, mesmo os supostamente mais áridos, caso os compêndios em uso para a formação dos Mestres Engenheiros, os quais, porém, continuam a recorrer à narrativa histórica e às fontes ou citações antigas, que, em nenhum modo,

40 O herói "se agradou tanto do deleitoso sítio (...), que julgou ser este porto o melhor que tinha visto"; op.cit.: 2.1., 3; id.: 2.5., 17.

41 Op.cit.: 2.9., 32-33. Possidónio e Artemidoro eram os Autores em que Estrabão baseava a suas exposições sobre a Turdetânia (Geog., 3.1.4; 3.2.4; etc.); cf. também Caetano 2007.

42 Azevedo 1753 (1652): 2.24., 89; 2.25, 94-95. A indicação da visita de Catão era retirada da obra de Frei Bernardo de Brito, apoiando-se numa epígrafe, presumivelmente falsa (cf. Alarcão 1988: 124).

43 Op. cit.: 3.9, 3.10. Há referência a epígrafes sacerdotais e o caso de uma inscrição (“da Porta de Alfofa") de um "legado perpétuo do Imperador" (op. cit.: ibid., 42).

44 Op. cit.: 3.20., 77-78; id.: 3.22., 86 e 3.25., 97.

45 Op. cit.: 3.28., 105-110. 
será um registo acessório, antes indica o grau da própria cultura dos grupos sociais envolvidos - sendo, em rigor, uma cultura com base nos Clássicos, na ciência, como nas Letras.

Compondo-se cada texto enquanto somatório de elementos recolhidos na sucessão de outros textos, e estando evidentemente já distantes os tempos de Vitrúvio, mantinha-se, como síntese para períodos modernos, esta consagração da arte de fortificar que o Engenheiro romano preconizara em teoria e método, consolidando-se como actividade. Autonomizava-se em texto e explicava-se pela História, tanto quanto se compreendia pela Ciência e pela Geometria, merecendo citações devidamente recolhidas em fontes de irrecusável autoridade, onde se continuava a exprimir a excelência da cultura, em formulação adequada à necessidade de opportunitas de períodos modernos, aqui coincidentes com os contextos subsequentes à Restauração.

A criação de Aulas de Arquitectura e Fortificação, foi assim acompanhada de textos correlativos com a necessidade de preparação técnica para o fomento de obras, neste caso sobretudo militares, com auge entre os séc. XVI- XVII e dirigindo-se por fim à reconstrução das praças e fortes da Restauração. As bases científicas e culturais, mantêm-se, ainda como no Renascimento, apoiadas no amplo recurso à citação de obras e Autores antigos, numa definição de atitudes que se distinguem porventura como uma marca de época.

Observamos com esta literatura a afirmação de uma cultura apologética, contendo as súmulas do que se recebera de herança antiga, e em que o conceito de ciuitas se expandia pelo novo conceito de Nação, o que também justificava a recuperação da memória dos gestos e lugares, mesmo em textos destinados à aprendizagem técnica e científica; de resto, conforme observado, também a ciência, até finais do séc. XVII, recolhia o que vinha da Antiguidade. Há um carácter humanistíco subjacente, no respeito pelas fontes e citações de períodos antigos, convergindo num mesmo saber, História e scientia, exaltando-se a realização edificada como expressão perene da Razão mas também expressão de memória. 


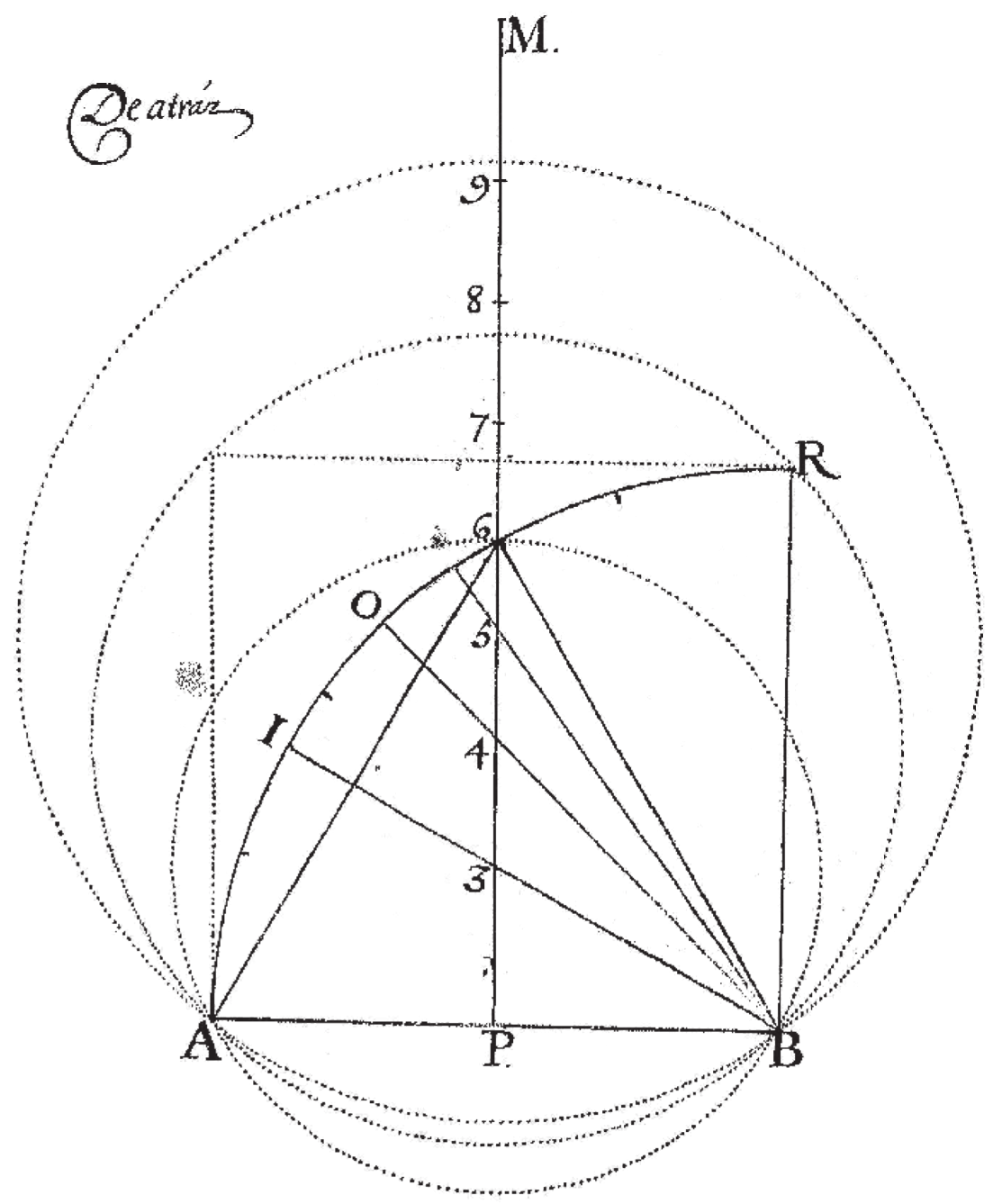

Figura:

Construção geométrica, in Luís Serrão Pimentel e Diogo Pardo Osório, Architectura militar ou Fortificação (1659, BA 49 III-4), fl $27 \mathrm{v}^{\circ}$.

Sob autorização da Biblioteca Nacional da Ajuda, Lisboa. 


\section{Bibliografia}

Alarcão, J. (1988), Roman Portugal, Vol. 2.2., Warminster: Aris and Phillips.

Albuquerque, L. (1974 a), «A 'Aula da Esfera' do Colégio de Santo Antão no século XVII», in Albuquerque, L. Estudos de História, Vol. 2. Coimbra: Universidade de Coimbra.

Albuquerque, L. (1974 b), «Fragmentos de Euclides numa versão portuguesa do séc. XVII», in Albuquerque, L. Estudos de História, Vol. 1. Coimbra: Universidade de Coimbra.

Argan, G.C. (1998 [1984]), A História da Arte Como História da Cidade, São Paulo: Martins Fontes.

Azevedo, L. Marinho (1753 [1652]), Fundação, Antiguidades e Grandezas da Mui Insigne Cidade de Lisboa, e Seus Varoens Ilustres em Santidade, Armas e Letras (...), Lisboa: Oficina de Manuel Soares.

Brasillach, R. (1950), Anthologie de la poésie grècque, Paris: Librairie Stock - Le Livre de Poche Classique.

Caetano, M. T. (2007), “O 'Último Porto de Ulisses'. História, Urbanismo e arte da Felicitas Iulia Olisipo", in Revista de História da Arte, Vol. 4, Lisboa: Instituto de História da Arte - Instituto de História da Arte - Faculdade de Ciências Sociais e Humanas da Universidade Nova de Lisboa.

Choay, F. (2007), A Regra e o Modelo. Sobre a Teoria da Arquitectura e do Urbanismo. Casal de Cambra: Caleidoscópio Editora.

Dodds, E. R. (1970), «Proclus», in N.G.L. Hammond (ed.), The Oxford Classical Dictionary, Oxford: Clarendon Press [2a edição].

Granger, F. ed. (1996 [1934]), Vitruvius. On Architecture. Vol. 2: Books VI-X, Cambridge - Massachussets, Londres: Harvard University Press.

Granger, F. ed. (1995 [1931]), Vitruvius. On Architecture. Vol. 1: Books I-V, Cambridge - Massachussets, Londres: Harvard University Press.

Harl, K. W. (1990), «Sacrifice and pagan belief in $5^{\text {th }}$. and $6^{\text {th }}$ - Century Byzantium», in Past and Present. Journal of Historical Studies, $\mathrm{N}^{\circ} 128$, Oxford: The Past and Present Society

Heath, T.L. e Toomer, G.J. (1970), «Euclid», in N.G.L. Hammond (ed.), The Oxford Classical Dictionary, Oxford: Clarendon Press [2 $2^{\mathrm{a}}$ edição].

Maciel, M. J. ed. (2006), Vitrúvio. Tratado de Arquitectura. Lisboa: IST - Press.

Maciel, M.J. (2000), «Entre Constâncio II e Juliano: A linguagem de Potâmio de Lisboa e o conhecimento da Lusitânia do séc. IV», in Revista da Faculdade 
de Ciências Sociais e Humanas, $N^{o}$ 13: «Cognição e Linguagem», Lisboa: Edições Colibri.

Mellor, R. ed. (1998), The Historians of Ancient Rome. An Anthology, Nova Iorque - Londres: Routledge.

Mello, M. M. e Leitão, H. (2005), “A pintura barroca e a cultura matemática dos Jesuítas. O Tractado de Prospectiva de Inácio Vieira, sj (1715)”, in Revista de História da Arte, Vol. 1, Lisboa: Instituto de História da Arte - Instituto de História da Arte - Faculdade de Ciências Sociais e Humanas da Universidade Nova de Lisboa.

Monteiro, J. G.; Braga, J. E. (2009), Vegécio: Compêndio da Arte Militar, Coimbra: Universidade de Coimbra.

Moreira, R. (1999), «Um Tratado Português de Arquitectura do século XVI (15761579)», in W. Rossa e R. Araújo (eds.), Universo Urbanístico Português. 1415-1822, Lisboa: Comissão Para a Comemoração dos Descobrimentos Portugueses.

Moreira, R. (1989), «Tratados de Arquitectura», in J. F. Pereira (coord.), Dicionário de Arte Barroca em Portugal. Lisboa: Editorial Presença.

Moreira, R. (1987), «A Aula de Arquitectura do Paço da Ribeira e a Academia das Matemáticas de Madrid», in P. Dias (coord.), Actas do II Simpósio de História da Arte: As Relações Artísticas entre Portugal e Espanha na Época dos Descobrimentos. Coimbra: Instituto de História da Arte da Universidade de Coimbra.

Moreira, R. (1986), «Do rigor teórico à urgência prática. A arquitectura militar», in C. Moura (coord.), História da Arte em Portugal. Vol. 8. Lisboa: Publicações Alfa.

Patrocínio, M. F. S. (2010), «A monumentalidade antiga e o ideal de dignificação da cidade em Autores Portugueses dos sécs. XVI-XVIII», in L. Santa Bárbara (org.), Identidade e Cidadania da Antiguidade aos nossos dias. Actas do VI Congresso Internacional da APEC, Porto: Papiro Editora.

Patrocínio, M. F. S. (2006), «O registo das antiguidades lusitânicas do Sul no legado documental de D. Manuel do Cenáculo», in Promontoria. Revista do Departamento de História, Arqueologia e Património - Universidade do Algarve, $\mathrm{N}^{\mathrm{o}}$ 4, Faro: Universidade do Algarve.

Pimentel, L. S. e Osório, D. P. (1659), Architectura militar ou Fortificação, Dictada por Luiz Serrão Pimentel [a Dom Diogo Pardo de Osório] em 27 de Outubro de 1659. BA Ms 49 III-4.

Rocha Pereira, M. H. (1979), Estudos de História da Cultura Clássica, Vol. 1: «Cultura Grega», Lisboa: Fundação Calouste Gulbenkian [5ª edição]. 
Serrão, V. (2003), História da Arte em Portugal - O Barroco, Lisboa: Editorial Presença.

Smith, G. R. (1993), Architectural Diplomacy. Roman and Paris in Late Baroque, Nova Iorque: The Architectural History Foundation - MIT Press.

Serrão, V. (2003), História da Arte em Portugal - O Barroco, Lisboa: Editorial Presença.

Smith, G. R. (1993), Architectural Diplomacy. Roman and Paris in Late Baroque, Nova Iorque: The Architectural History Foundation - MIT Press.

Tavares, D. (2007), António Rodrigues. Renascimento em Portugal, Porto: Dafne Editora.

Tiago de Oliveira, J. (1989), O Essencial Sobre a História das Matemáticas em Portugal. Lisboa: Imprensa Nacional - Casa da Moeda.

Wilkinson, C. (1988), «Renaissance Treatises on Military Architecture and Science of Mechanics», in J. Guillaume (ed.), Les traités d'Architecture de la Renaissance. Actes du Congrès tenu à Tours. Paris: Picard - J.P. Getty Trust - Université de Tours.

Xavier, J. P. (2006), Sobre as Origens da Perspectiva em Portugal. O Liuro de Prespectiua do Códice 3675 da Biblioteca Nacional, Porto: FAUP Publicações. 